\title{
Prevalence and risk factors of diabetic retinopathy among an elderly population with diabetes in Nepal: the Bhaktapur Retina Study
}

This article was published in the following Dove Press journal:

Clinical Ophthalmology

\section{Raba Thapa' \\ Shankha N Twyana ${ }^{2}$ \\ Govinda Paudyal' \\ Shankar Khanal ${ }^{3}$ \\ Ruth van Nispen ${ }^{4}$ \\ Stevie $\operatorname{Tan}^{4}$ \\ Suman S Thapa ${ }^{5}$ \\ GHMB van Rens ${ }^{4}$}

'Vitreo-retina Department, Tilganga Institute of Ophthalmology, Kathmandu, Nepal; ${ }^{2}$ Department of Eye Bank, Tilganga Institute of Ophthalmology, Kathmandu, Nepal; ${ }^{3}$ Central Department of Statistics, Tribhuvan University, Kirtipur, Nepal; ${ }^{4}$ Department of Ophthalmology and the Amsterdam Public Health Research Institute, Vrije University Medical Center, Amsterdam, the Netherlands; ${ }^{5} \mathrm{Glaucoma}$ Department, Tilganga Institute of Ophthalmology, Kathmandu, Nepal
Correspondence: Raba Thapa Vitreo-retina Department, Tilganga Institute of Ophthalmology, PO Box 56I, Kathmandu, Nepal

Tel +977 I 4493775

Fax +977 | 4474937

Email rabathapa@live.com
Aim: Diabetic retinopathy (DR) is an emerging cause of blindness in developing countries. This study aimed to explore the prevalence and risk factors of DR in an elderly population in Nepal.

Subjects and methods: This is a population-based, cross-sectional study. A total of 1860 subjects at the age 60 years and above participated (response rate $88.6 \%$ ). A detailed history was obtained, presenting and best-corrected visual acuity were measured, and anterior segment and posterior segment examinations were carried out. Blood pressure and random blood sugar were recorded; body mass index was calculated, and abdominal girth was measured. DR was graded by clinical examination using Early Treatment Diabetic Retinopathy Study criteria.

Results: Diabetes was found in 168 (9\%) subjects (mean age 69.6 years), 31 (18.5\%) of whom were newly diagnosed. The prevalence of DR was $23.8 \%$ (95\% confidence interval [CI]: $17.7 \%-31 \%$ ) among the persons with diabetes. The prevalence of DR among newly diagnosed subjects with diabetes was $6.5 \%$ (95\% CI: $0.8 \%-21.4 \%)$. The prevalence of vision-threatening DR was $9.5 \%$ (95\% CI: $5.5 \%-15 \%)$ and was higher in males. The prevalence of DR was $83.3 \%$ (95\% CI: $35.9 \%-99.6 \%$ ) among those with diabetes for over 20 years. In multivariable logistic regression analysis, duration of diabetes, hypertension, and alcohol consumption were significantly associated with DR.

Conclusion: DR is a common problem among the elderly population with diabetes in Nepal. The duration of diabetes, hypertension, and alcohol consumption are the risk factors for the development of DR. Strategies have to be developed for timely diagnosis of diabetes and screening for DR.

Keywords: prevalence, elderly, risk factors, diabetic retinopathy, Nepal

\section{Introduction}

Diabetic retinopathy (DR) is an emerging cause of blindness, especially in developing countries. ${ }^{1}$ More than $80 \%$ of blinding sequelae of DR have been reported from the developing world. ${ }^{1-3}$ Likewise, DR is the most common cause of blindness among the working age group in the developed world and is the fifth leading cause of global blindness. ${ }^{4-8}$ Approximately one-third of the diabetic populations have DR, and among them, one-third have vision-threatening DR that needs immediate treatment. ${ }^{2}$ The global prevalence of DR among people with diabetes has been reported to be $34.6 \%$, and the prevalence of DR in the developed world approximates to $40.3 \%{ }^{3-5}$ Several population-based studies from the developing world have however reported a lower prevalence of DR among the diabetic population, in the range of $10 \%-20 \% .^{9-12}$ 
Identification and timely management of modifiable risk factors such as glycemic control, concurrent hypertension, hyperlipidemia, nephropathy, anemia, and smoking could help reduce the associated sight-threatening complications. ${ }^{12-17}$ Routine screening for diabetes is not a common practice in developing countries, and poor glycemic control has been identified as the leading cause of DR among newly diagnosed and known diabetics. ${ }^{14,18}$ This has been compounded by low awareness of DR and its risk factors. ${ }^{18,19}$

There are limited population-based studies in Nepal that have assessed the risk factors of DR., ${ }^{9,10}$ The rationale for conducting the Bhaktapur Retina Study (BRS) was that in a previous study, the Bhaktapur Glaucoma Study (BGS) conducted in 2007, a substantial number of subjects were found with retinal diseases. ${ }^{9}$ The BGS estimated that retinal diseases were the second major cause of blindness following cataract. This study aims to explore the prevalence and various risk factors of DR among the diabetic population aged 60 years and above in one of the districts of Nepal.

\section{Subjects and methods Study population}

Bhaktapur district, located in the Kathmandu valley of Nepal, has a population of 304,651 , of whom 76,540 are above the age of 40 years. ${ }^{20}$ This district has 2 municipalities and 161 village development committees. The sampling frame for BRS is based on the same sampling frame of BGS conducted 7 years ago. ${ }^{21}$ The 30 -cluster sampling method of the World Health Organization (WHO) was used. ${ }^{21,22}$ From the 30 clusters, a house-to-house enumeration was done and a name list was prepared. Using the Epi Info software, version 3.5.1.17, 4,800 subjects older than 40 years were selected. ${ }^{22}$ The prevalence of vitreoretinal disorders in the 40- to 49- and 50 - to 59-year age groups, which counted for over $60 \%$ of the study population, was found to be low in the BGS. Given this low prevalence and the restricted budget, among these subjects, only those older than 60 years at the commencement of BRS were reinvited for an examination for the retinal study. The required sample size for the BRS was estimated to be 2,100 subjects after assuming a $7 \%$ prevalence for vitreoretinal disorders among individuals 60 years or older, a relative precision of $25 \%$, an $85 \%$ compliance, and a design effect of $2 .{ }^{9}$ Of the total study population of BGS, the number of those who were 60 years and above was 2,151. Among these, a total of $1,334(62 \%)$ subjects were enrolled in the BRS, 323 (15\%) had passed away, 108 (5\%) had moved to other places, and $388(18 \%)$ did not participate again. To achieve the required number $(2,100)$ of participants, we added extra clusters in a similar pattern as the BGS to this study and selected the rest of the participants, $766(38 \%)$, using the same procedure. Two female community health workers visited the subjects at their homes, and participants were referred to the primary eye care center of Bhaktapur district for a detailed evaluation. The prevalence and risk factors of DR were assessed in the sample of the BRS. The prevalence of DR in Nepal was reported to be $18 \%$ for those 40 years and above..$^{10}$ Based on the above study, we assumed a higher prevalence of DR of $27 \%-28 \%$ in the elderly people with diabetes. The sample size required for diabetic subjects with $80 \%$ power was 157 . The study was conducted from August 2013 to December 2015. The demographics of both participants and nonparticipants were recorded.

A special questionnaire to assess the prevalence and risk factors of diabetes and DR was developed. Mid-level ophthalmic personnel conducted the interview, and 2 ophthalmologists examined the participants. Fifty questionnaires were pretested by the retina specialist and mid-level ophthalmic personnel. There were no difficulties in understanding the questionnaire by either the mid-level ophthalmic personnel or participants. The medical and pharmaceutical histories were taken while interviewing the patients. If the subjects were able to read and write in the national language, they were categorized as literate as defined by the Government of Nepal. The predominant profession of working age was considered as the occupation.

The study was approved by the Institutional Review Board and Ethics Committee of Tilganga Institute of Ophthalmology (TIO) and conducted in accordance with the Declaration of Helsinki. Informed consent was written in the vernacular and was read out for those unable to read. Subjects were asked to sign the consent form, and thumb impressions were taken for those unable to sign, prior to enrollment in the study. The thumb impression as a form of informed consent was approved by the Institutional Review Board and Ethics Committee of TIO.

\section{Patient examination and DR assessment}

All patients underwent an anterior segment examination, dilated fundus examination, and measurement of intraocular pressure. Presenting and best-corrected visual acuity (BCVA) with pin hole and refraction were assessed using the logarithm of minimum angle of resolution (logMAR) with tumbling E charts placed at $4 \mathrm{~m}$ (4 meter original series Early Treatment Diabetic Retinopathy Study Chart; Precision Vision, Woodstock, IL, USA). Streak retinoscopy (Beta 200; Heine, Herrsching, Germany) was performed for objective 
refraction which was followed by subjective refraction. If the subjects were not able to read the $\log$ MAR 1.0 line, the vision was again checked at $1 \mathrm{~m}$. If the subjects were unable to recognize any of the largest optotypes, then perception of hand movement was checked. If hand movement was also not recognized, then the presence of light perception was checked and recorded in the proforma.

DR was graded using Early Treatment Diabetic Retinopathy Study criteria by retina specialists at clinical examination. ${ }^{23}$ Vision-threatening retinopathy was diagnosed if subjects had severe nonproliferative DR, proliferative DR, or clinically significant macular edema in at least 1 eye.

\section{Assessment and operationalization of risk factors}

Detailed history was taken using a standardized questionnaire. Age, gender, education status, occupation, smoking, alcohol consumption, diabetes duration, treatment of diabetes with oral hypoglycemic agents or insulin, and presence of other concurrent systemic problems such as hypertension, hyperlipidemia, or other cardiac disorders were elicited from the administrated standardized questionnaire. Those who reported consumption of any type of alcoholic beverages were considered as alcohol consumers. They were classified as present drinkers, past drinkers, and no alcohol consumption. The amount of alcohol consumed however was not recorded. Similarly, those who reported history of smoking were considered as smokers and further classified as present smokers, past smokers, and never smoked. The number of cigarettes smoked per day was recorded. All subjects underwent blood examination for non-fasting blood sugar levels. Random blood sugar was recorded by the glucose oxidase peroxidase method using the Stat Fax 3300 equipment (Awareness Technology, Westport, CT, USA). Diagnosis of diabetes mellitus was based on either the use of diabetic medications or a non-fasting blood sugar level of $200 \mathrm{mg} / \mathrm{dL}$ or greater. ${ }^{9,24}$

Blood pressure (BP), height, weight, and abdominal girth were measured. Hypertension was defined if the systolic BP was $140 \mathrm{mmHg}$ or more, diastolic BP was $90 \mathrm{mmHg}$ or more, or if the patient used any antihypertensive medications. Pulse pressure was calculated by subtracting diastolic BP from systolic BP.

Body weight and height were measured using standard technique, and body mass index (BMI) was calculated. Underweight, overweight, and obesity were defined as per the WHO criteria. Underweight is a BMI less than 18.5, normal is a $\mathrm{BMI}$ between 18.5 and 25 , overweight is a $\mathrm{BMI}$ equal to or greater than 25 , and obesity is a BMI equal to or greater than 30. Similarly, abdominal girth was measured in centimeters using a standard technique. Briefly, abdominal girth was measured at the midpoint between the lowest rib and the top of the hip bone (iliac crest) using a measuring tape.

\section{Statistical analysis}

Mean \pm standard deviation were calculated for continuous variables, and percentages for categorical variables. Comparisons of continuous variables between 2 groups were performed using independent $t$-tests, and associations between 2 categorical variables were assessed through chisquare or Fisher's exact tests whenever applicable, and the association between ordinal or categorical variables and nominal variables was assessed through rank sum (MannWhitney) tests.

Among persons with diabetes, any DR and/or visionthreatening DR vs no DR was analyzed as binary outcome. Univariate and multiple logistic regression models were used to identify significant risk factors. The potential risk factors for final multiple logistic regression models were selected through the use of a stepwise forward selection procedure with an entry probability of 0.05 and a removal probability of 0.10 . All the independent variables in the univariate logistic regression were considered candidate variables for multiple logistic regression models. All the statistical analyses were performed using STATA 13.0.

\section{Results}

Complete information was available for 1,860 subjects ( $88.6 \%$ of the total sample). There was no significant difference observed in the age and gender between the responders and nonresponders (Table 1).

The characteristics of the study population are shown in Table 2. Age ranged from 60 to 95 years and 1,039 (55.9\%) were female, $77 \%$ were illiterate, and $72.6 \%$ were farmers by occupation. Diabetes was found in 168 subjects ( $9 \%$; 95\% confidence interval [CI]: 7.7-10.4); among them, 31 (18.5\%; 95\% CI: 12.9-25.2) were newly diagnosed. Among subjects with diabetes, $65 \%$ (95\% CI: $57.2-72.1)$ were in

Table I Comparison of responders and nonresponders in the study population

\begin{tabular}{llll}
\hline Variable & $\begin{array}{l}\text { Responders } \\
(\mathbf{N}=\mathbf{I}, \mathbf{8 6 0})\end{array}$ & $\begin{array}{l}\text { Nonresponders } \\
(\mathbf{N}=\mathbf{2 4 0})\end{array}$ & p-value \\
\hline Mean age (years) & $69.6 \pm 7.3$ & $69.5 \pm 7.9$ & 0.782 \\
Male, n (\%) & $821(44.1)$ & $110(45.8)$ & 0.629 \\
Female, $\mathrm{n}(\%)$ & $\mathrm{I}, 039(55.9)$ & $130(54.2)$ & \\
\hline
\end{tabular}


Table 2 Demographic characteristics of participants in the Bhaktapur Retina Study

\begin{tabular}{|c|c|c|c|c|c|c|c|}
\hline Characteristics & $\begin{array}{l}\text { All persons } \\
(\mathrm{N}=1,860)\end{array}$ & $\begin{array}{l}\text { Persons without } \\
\text { diabetes }(\mathrm{N}=1,692)\end{array}$ & $\begin{array}{l}\text { Persons with } \\
\text { diabetes }(\mathrm{N}=168)\end{array}$ & $p$-value & $\begin{array}{l}\text { Males with } \\
\text { diabetes }(\mathrm{N}=73)\end{array}$ & $\begin{array}{l}\text { Females with } \\
\text { diabetes }(\mathbf{N}=95)\end{array}$ & $p$-value \\
\hline Age (years), mean $\pm S D$ & $69.6 \pm 7.3$ & $69.8 \pm 7.4$ & $67.9 \pm 6.7$ & 0.002 & $66.7 \pm 6.2$ & $68.9 \pm 6.9$ & 0.035 \\
\hline Male gender, n (\%) & $821(44.1)$ & $748(44.2)$ & $73(43.5)$ & 0.851 & - & - & - \\
\hline Agricultural occupation, n (\%) & I,35I (72.6) & $\mathrm{I}, 240(73.3)$ & III (66.I) & 0.045 & $50(68.5)$ & $61(64.2)$ & 0.623 \\
\hline Other occupations, n (\%) & $509(27.4)$ & $452(26.7)$ & $57(33.9)$ & - & $23(31.5)$ & $34(35.8)$ & \\
\hline Illiterate, n (\%) & $\mathrm{I}, 433(77.0)$ & $\mathrm{I}, 323(78.2)$ & $110(65.5)$ & $<0.001$ & $33(45.2)$ & $77(81.1)$ & $<0.001$ \\
\hline
\end{tabular}

the age group 60-69 years, $28 \%(95 \%$ CI: $21.3-35.1)$ in the age group 70-80 years, and 7\% (95\% CI: 2.9-9.6) in the age group 80 years and above.

In comparison with nondiabetic subjects, those with diabetes were younger $(p=0.002)$ and more often illiterate $(p<0.001)$. Type of occupation was significantly associated $(p=0.045)$ with diabetes.

The prevalence of DR among diabetics was 23.8\% (95\% CI: 17.6-31.0) which was almost equal to the age- and sexadjusted prevalence of DR; 23.9\% (95\% CI: 17.5-30.3) (Table 3$)$. The prevalence of DR was 22\% (95\% CI: 14.6-30.9) in the age group 60-69 years, 27.7\% (95\% CI: $15.6-42.6)$ in the age group 70-79 years, and 25\% (95\% CI: 5.5-57.2) in the age group 80 years and above. Differences found between males and females were not statistically significant. The prevalence of DR among known diabetics was significantly higher $(p=0.012)$ than among newly diagnosed subjects. Macular edema was found at 4.2\% $(95 \%$ CI: 1.7-1.4) among diabetics. The prevalence of macular edema among known diabetics was 4.4\% (95\% CI: 1.6-9.3), which was slightly greater than among those newly diagnosed with diabetes $(3.2 \%$; 95\% CI: $0.8-16.7)$ but statistically not significant $(p=0.77)$. Vision-threatening DR was found in 9.5\% (95\% CI: 5.5-15.0) and was found more often among the known diabetics $(10.2 \%$; 95\% CI: 5.70-16.6), but was also statistically not significant $(p=0.74)$. Hypertension was found in $34.6 \%$, of whom $12 \%$ were newly diagnosed (Table 3).
The duration of diabetes ranged from 0 to 30 years, and the mean duration was $5.7 \pm 6.2$ years. DR was found in $17.9 \%$ (95\% CI: $11.9-25.2)$ of subjects with diabetes for less than 10 years, $45.5 \%$ (95\% CI: 24.4-67.8) among those with diabetes for 11-20 years, and 83.3\% (95\% CI: 35.9-99.6) among those with diabetes for over 20 years. Vision-threatening DR was found more often in study subjects with a longer duration of diabetes (Table 4).

Table 5 presents the associations of various risk factors in relation to DR and vision-threatening retinopathy among diabetics. In univariate logistic regression analysis, 5 factors including duration of diabetes (odds ratio [OR], 2.2 per 5-year increase), systolic BP (OR, 1.1 per $5 \mathrm{mmHg}$ increase), pulse pressure (OR, 1.1 per $5 \mathrm{mmHg}$ increase), hypertension (OR, 2.3 compared to non-hypertensive), and alcohol consumption (OR, 3.0 compared to no alcohol consumption) were found highly associated with odds of developing any type of DR. Similarly, the duration of diabetes (OR, 1.9 per 5-year increase), pulse pressure (OR, 1.2 per $5 \mathrm{mmHg}$ increase), and alcohol consumption (OR, 6.2 compared to no alcohol consumption) were also associated with vision-threatening DR.

There was no significant association of DR with underweight, overweight, and obesity ( $p=0.634)$. Age, gender, occupation, literacy, smoking, BMI, abdominal girth, BCVA, and non-fasting blood sugar had no significant association with development of DR and vision-threatening DR.

In multivariable logistic regression analysis, duration of diabetes and alcohol consumption were significantly

Table 3 Prevalence of diabetic retinopathy and macular edema among the diabetic subjects

\begin{tabular}{|c|c|c|c|c|c|c|c|}
\hline Characteristics & $\begin{array}{l}\text { Persons with } \\
\text { diabetes }(N=168)\end{array}$ & $\begin{array}{l}\text { Males } \\
(\mathrm{N}=73)\end{array}$ & $\begin{array}{l}\text { Females } \\
(\mathrm{N}=95)\end{array}$ & $p$-value & $\begin{array}{l}\text { Newly diagnosed } \\
\text { diabetes }(\mathrm{N}=3 \mathrm{I})\end{array}$ & $\begin{array}{l}\text { Known diabetes } \\
(\mathrm{N}=137)\end{array}$ & $p$-value \\
\hline Any retinopathy & $23.8(|7.6-3| .0)$ & $26.0(16.5-37.6)$ & $22.1(|4.2-3| .8)$ & 0.587 & $6.5(0.8-21.4)$ & $27.7(20.4-36.1)$ & 0.012 \\
\hline \multicolumn{8}{|l|}{ Retinopathy grades } \\
\hline None & $76.2(69.0-82.4)$ & $74.0(62.4-83.5)$ & $77.9(68.2-85.8)$ & 0.534 & $93.6(78.6-99.2)$ & $72.3(64-79.6)$ & 0.020 \\
\hline Mild NPDR & $4.2(1.7-8.4)$ & $5.5(1.5-13.4)$ & $3.2(0.7-9)$ & & 0 & $5.1(2.1-10.2)$ & \\
\hline Moderate NPDR & $10.7(6.5-16.4)$ & $9.6(3.9-18.8)$ & $11.6(5.9-19.8)$ & & 0 & |3.| (8-20) & \\
\hline Severe NPDR & $7.1(3.7-12.1)$ & $8.2(3.1-17.1)$ & $6.3(2.4-13.2)$ & & $3.2(0.1-16.7)$ & $8.0(4.1-13.9)$ & \\
\hline PDR & $1.8(0.4-5.1)$ & $2.7(0.3-9.5)$ & I.0 (0.02-5.7) & & $3.2(0.1-16.7)$ & $1.5(0.2-5.2)$ & \\
\hline Macular edema & $4.2(1.7-8.4)$ & $2.7(0.3-9.5)$ & $5.3(1.7-11.9)$ & 0.4187 & $3.2(0.8-16.7)$ & $4.4(1.6-9.3)$ & 0.766 \\
\hline Vision-threatening DR & $9.5(5.5-15.0)$ & II.0 (4.86-20.5) & $8.4(3.7-15.9)$ & 0.605 & $6.5(0.8-21.4)$ & $10.2(5.7-16.5)$ & 0.739 \\
\hline
\end{tabular}

Note: Data are presented as $\mathrm{n}(95 \% \mathrm{Cl})$.

Abbreviations: NPDR, nonproliferative diabetic retinopathy; PDR, proliferative diabetic retinopathy; DR, diabetic retinopathy. 
Table 4 Prevalence of diabetic retinopathy and duration of diabetes among diabetic subjects

\begin{tabular}{|c|c|c|c|c|c|c|}
\hline \multirow{2}{*}{$\begin{array}{l}\text { Duration } \\
\text { of diabetes } \\
\text { (years) }\end{array}$} & \multicolumn{5}{|c|}{ DR diagnosis, $\mathbf{n}(\%)$} & \multirow{2}{*}{$\begin{array}{l}\text { Overall prevalence of } \\
\text { DR\% }(95 \% \mathrm{Cl})\end{array}$} \\
\hline & $\begin{array}{l}\text { No DR } \\
(\mathrm{N}=128)\end{array}$ & $\begin{array}{l}\text { Mild NPDR } \\
(\mathrm{N}=7)\end{array}$ & $\begin{array}{l}\text { Moderate } \\
\text { NPDR }(\mathrm{N}=18)\end{array}$ & $\begin{array}{l}\text { Severe NPDR } \\
(\mathbf{N}=12)\end{array}$ & $\begin{array}{l}\text { Proliferative } \\
\text { DR }(\mathrm{N}=3)\end{array}$ & \\
\hline$\leq 10$ years & $115(82.1)$ & $5(3.6)$ & II (7.8) & $7(5)$ & $2(1.4)$ & $17.9(11.9-25.2)$ \\
\hline II-20 years & $12(54.5)$ & $2(9.1)$ & $3(13.6)$ & $4(18.2)$ & I (4.5) & $45.5(24.4-67.8)$ \\
\hline$\geq 21$ years & I (I6.7) & 0 & $4(66.7)$ & I (I6.7) & 0 & 83.3 (35.9-99.6) \\
\hline
\end{tabular}

Abbreviations: DR, diabetic retinopathy; NPDR, nonproliferative diabetic retinopathy.

associated with DR (OR, 2.4; 95\% CI: 1.7-3.5; $p<0.001$; and OR, 4.3; 95\% CI: 1.6-11.3; $p=0.004$, respectively) as well as with vision-threatening DR (OR, 2.3; 95\% CI: 1.4-3.6; $p<0.001$; and OR, 8.6; 95\% CI: 1.7-47.2; $p=0.010$, respectively). Besides these, high systolic BP was significantly associated with DR (OR, 1.1; 95\% CI: 1.02-1.2; $p=0.018$ ) (Table 6).

\section{Discussion}

This study was conducted to assess the prevalence and risk factors of DR in a large population of Nepal. Although our findings may not be representative of the entire country, the results can be extrapolated for adjoining districts with similar socioeconomic, demographic, cultural, and geographic conditions. Among the age group 60 years and above in the Bhaktapur district, we found a diabetes prevalence of $9 \%$. A finding of concern is the high number of newly diagnosed diabetics among the total diabetics (18.5\%). The prevalence of undiagnosed diabetes were similar to findings from India (17.6\%), our neighboring country. ${ }^{13}$ Lack of awareness and limited access to medical examination could have been responsible for the large number of undiagnosed cases. ${ }^{18,19}$
The prevalence of DR among persons with diabetes in our study was $23.8 \%$. This was higher than previous reports from various population-based studies in Nepal $(10 \%$ $19 \%)^{9,10}$ and other developing countries $(10 \%-18 \%) .{ }^{11-13,25-27}$ This disparity however could be caused by the differences between the age cut-off in the study populations (in our study $\geq 60$ years). The DR prevalence in our study was less than the overall global prevalence $(34.6 \%) .{ }^{1-8}$ This finding is consistent with reports of lower prevalence of DR within the developing world. ${ }^{4}$ The differences in DR prevalence may be due to a longer life expectancy in the developed world. DR was found in 22\% (95\% CI: 14.6-30.9) in the age group 60-69 years, $27.7 \%(95 \% \mathrm{CI}: 15.6-42.6)$ in the age group 70-79 years, and 25\% (95\% CI: 5.5-57.2\%) in the age group 80 years and above in our study. A study by Thapa et al found that the prevalence of DR ranged from $8 \%$ to $28.5 \%$ in the age group 60 years and older among inhabitants in the same study region 7 years earlier than our study, where the prevalence of DR was $16.8 \%(95 \%$ CI: 9.7-26.2) in the age group 60-69 years, 7.8\% (95\% CI: 2.1-18.9) in the age group 70-79 years, and $14.3 \%(95 \%$ CI: $0.4-57.9 \%$ ) in the age group 80 years and above. ${ }^{9}$ The

Table 5 Risk factors for diabetic retinopathy and vision-threatening retinopathy among diabetics in univariate logistic regression analysis

\begin{tabular}{|c|c|c|c|c|}
\hline \multirow[t]{2}{*}{ Characteristics } & \multicolumn{2}{|l|}{ Any retinopathy } & \multicolumn{2}{|c|}{ Vision-threatening retinopathy } \\
\hline & Odds ratio $(95 \% \mathrm{Cl})$ & $p$-value & Odds ratio $(95 \% \mathrm{Cl})$ & $p$-value \\
\hline Age (per 10 year increase in age) & I.2 (0.7-2.I) & 0.421 & $2.2(0.6-2.8)$ & $0.56 \mathrm{I}$ \\
\hline Gender (male vs female) & $0.8(0.4-1.6)$ & 0.554 & $0.7(0.3-2.1)$ & 0.553 \\
\hline Occupation (agriculture vs other occupation) & $0.8(0.4-1.7)$ & 0.548 & $\mathrm{I} . \mathrm{I}(0.4-3.2)$ & 0.853 \\
\hline Literacy (illiterate vs literate) & $1.2(0.6-2.5)$ & 0.650 & $0.9(0.3-2.8)$ & 0.851 \\
\hline Diabetes duration (per 5 year increase in duration) & $2.2(I .6 I-3.0 I)$ & $<0.001$ & $1.9(1.3-3.0)$ & 0.001 \\
\hline Non-fasting blood sugar (mg/dL) & $I(0.9-1)$ & 0.645 & I (0.9-1.0) & 0.291 \\
\hline Systolic BP (per 5 mmHg increase) & I.I (I.0I-I.20) & 0.022 & I.2(I.0-I.3) & 0.071 \\
\hline Pulse pressure (per 5 mmHg) & I.I (I.02-I.3) & 0.018 & $1.2(1.01-1.3)$ & 0.032 \\
\hline Hypertension & $2.3(1.0-4.9)$ & 0.040 & $2.6(0.8-8.4)$ & 0.119 \\
\hline Body mass index $\left(\mathrm{kg} / \mathrm{m}^{2}\right)$ & $0.9(0.9-1.0)$ & 0.265 & $0.9(0.8-1.1)$ & 0.390 \\
\hline Abdominal girth $(\mathrm{cm})$ & I $(0.9-1.0)$ & 0.175 & I $(0.9-1.0)$ & 0.319 \\
\hline Smoking & I.3 (0.6-2.7) & $0.47 \mid$ & $2.1(0.7-6.9)$ & 0.214 \\
\hline Alcohol consumption & $3.04(1.3-6.9)$ & 0.008 & $6.2(1.4-28.3)$ & 0.019 \\
\hline $\operatorname{BCVA}(<0.3$ vs $>0.3)$ & $1.2(0.6-2.5)$ & 0.665 & $0.8(0.3-2.7)$ & 0.744 \\
\hline
\end{tabular}

Abbreviations: BCVA, best corrected visual acuity; BP, blood pressure. 
Table 6 Risk factors for diabetic retinopathy among diabetics in multivariable logistic regression analysis

\begin{tabular}{|c|c|c|c|c|}
\hline \multirow[t]{2}{*}{ Characteristics } & \multicolumn{2}{|l|}{ Any retinopathy } & \multicolumn{2}{|c|}{ Vision-threatening retinopathy } \\
\hline & $\begin{array}{l}\text { Odds ratio ( } 95 \% \\
\text { confidence interval) }\end{array}$ & $p$-value & $\begin{array}{l}\text { Odds ratio }(95 \% \\
\text { confidence interval) }\end{array}$ & p-value \\
\hline Diabetes duration (per 5 year increase) & $2.4(1.7-3.5)$ & $<0.001$ & $2.3(1.4-3.6)$ & $<0.00 \mathrm{I}$ \\
\hline Alcohol consumption & $4.3(1.6-11.3)$ & 0.004 & $8.6(1.7-47.2)$ & 0.010 \\
\hline Systolic BP (per 5 mmHg increase) & I.I (I.02-I.2) & 0.018 & & \\
\hline
\end{tabular}

Abbreviation: BP, blood pressure.

overall prevalence of DR was low in this study compared to our present study. A possible reason could have been the underestimation of DR in the previous study as the BGS was focused primarily on glaucoma. A study in southern India reported a prevalence of DR of $10.2 \%$ in the age group 60-69 years and $14.8 \%$ in the age group 70 years and above; however, the prevalence of DR was lower than in our study. ${ }^{11}$ Interestingly, a study conducted in Finland reported a prevalence of DR of $20.5 \%$ in the age group $60-79$ years and $22.6 \%$ in the age group 70 years and above. Despite that these are figures from a developed country, our findings are almost similar. ${ }^{28}$

In our study, the prevalence of DR and vision-threatening DR was higher among males, which could have been due to lifestyle habits such as alcohol intake and cigarette smoking. This finding is similar to a study reported from India. ${ }^{12,26}$

The prevalence of DR among the newly diagnosed diabetics was $6.5 \%$. This indicates that diabetes had remained undiagnosed for a long duration. The prevalence of hypertension was $34.6 \%$ in our study, of whom $12 \%$ were newly diagnosed with hypertension. This could project a serious public health concern as irreversible visual impairment and blindness can occur due to late diagnosis of hypertension in combination with DR.

Among diabetics, the prevalence of vision-threatening DR was $9.5 \%$. This was similar to many studies from developing and developed countries., ${ }^{411}$ The prevalence of vision-threatening retinopathy in newly diagnosed subjects was $6.5 \%(\mathrm{~N}=2$, both were at a vision-threatening stage). After 20 years with diabetes, more than four-fifths (83.3\%) of the subjects had DR. These findings were consistent with studies from Nepal and other countries as well..$^{12,15,18}$

In multivariate analysis, duration of diabetes, high systolic BP, and alcohol consumption were significantly associated with DR. Similarly, duration of diabetes and alcohol consumption were also significantly associated with visionthreatening DR. Our findings were similar to hospitalbased and population-based studies in Nepal and other countries. $^{6-8,10,13,14,26,27}$
Studies regarding the association of DR and alcohol consumption are limited. Lee et al reported an increase in risk of deterioration of visual acuity with alcohol consumption, which was not associated with DR in individuals with type 2 diabetes. ${ }^{29}$ Moss et al also reported that moderate consumption of alcohol did not affect the occurrence of DR. ${ }^{30}$ However, Young et al reported alcohol consumption as an important independent factor associated with sightthreatening DR, which is similar to our findings. ${ }^{31}$ Drinking alcohol was a risk factor of DR in our study. There could be several reasons for this association. Poor glycemic control could have been due to the consumption of alcohol. Since our study did not evaluate the amount of alcohol intake or the consumption of alcohol with food, our discussions are based on assumptions. There are ongoing controversies on alcohol as a risk factor of DR. A recent meta-analysis by Zhu et al showed no significant association between alcohol intake and incidence of DR. Similarly on subgroup analysis, neither beer nor spirits were associated with risk of DR. Rather, wine and sherry were found to have a protective effect on DR. ${ }^{32}$ Another study by Fenwick et al has also reported the protective effect of moderate consumption of white and fortified wine associated with reduced odds of DR. ${ }^{33}$ Further studies are needed for the actual association of alcohol with DR in our population.

We did not find any significant association of smoking with DR, similar to other studies. ${ }^{16,17,34}$

There is low awareness in the community and among the persons with diabetes on diabetic eye disease, and a high prevalence of DR, including vision-threatening DR. It highlights the importance of DR awareness in the community and screening program using fundus camera by the allied ophthalmic personnel and with possible addition of recent technologies for DR detection in this community and similar other parts..$^{34-38}$

The strength of this study was the large sample size of an elderly age group with a high response rate. Although our findings are not representative of the entire country, results can probably be extrapolated for adjoining districts 
with similar socioeconomic, demographic, cultural, and geographic conditions. Random blood sugar level criteria used to diagnose diabetes mellitus could have underestimated the prevalence of diabetes. Another limitation was because of limited resources, and we were unable to assess the lipid profile, glycosylated hemoglobin, and proteinuria/ albuminuria of the participants for the analysis of risk factors of DR.

In conclusion, the overall prevalence of DR in this elderly population was relatively high among the subjects with diabetes. Furthermore, we found a considerable number of newly diagnosed diabetics who already had vision-threatening DR. Duration of diabetes, hypertension, and alcohol consumption were associated with an increased risk of developing DR. Timely diagnosis and treatment of diabetes and hypertension, avoiding excessive consumption of alcohol, and counseling on healthy dietary habits could help reduce the blinding sequelae of the disease. Given the low number of ophthalmologists in Nepal as well as the difficult geographic situation, screening for DR remains a challenge. Health programs that include digital fundus photographs to screen for DR could be a solution to enhance early detection of vision-threatening retinopathy in the future.

\section{Acknowledgments}

The authors would like to acknowledge Tilganga Institute of Ophthalmology, Kathmandu, Nepal, and Vrije University Medical Center, Amsterdam, the Netherlands, for funding this study. They would also like to acknowledge all the patients who participated in the study and the Bhaktapur Municipality. Professor Paul S Bernstein, MD, PhD, of the Moran Eye Center of the University of Utah, USA, edited the manuscript. The study was funded by Tilganga Institute of Ophthalmology and Department of Ophthalmology and Amsterdam Public Health Research Institute of Vrije University Medical Center.

\section{Author contributions}

All authors contributed toward data analysis, drafting and revising the paper and agree to be accountable for all aspects of the work.

\section{Disclosure}

The authors report no conflicts of interest in this work.

\section{References}

1. Wild S, Roglic G, Green A, Sicree R, King H. Global prevalence of diabetes. Estimates for the year 2000 and projections for 2030. Diabetes Care. 2004;27:1047-1052.
2. World Health Organization. Prevention of blindness from diabetes mellitus: report of a WHO consultation in Geneva. Geneva: World Health Organization; 2006.

3. Ruta LM, Magliano DJ, Lemesurier R, Taylor HR, Zimmet PZ, Shaw JE. Prevalence of diabetic retinopathy in type 2 diabetes in developing and developed countries. Diabet Med. 2013;30:387-398.

4. Yau JW, Rogers SL, Kawasaki R, et al. Global prevalence and major risk factors of diabetic retinopathy. Diabetes Care. 2012;35:556-564.

5. Eye Diseases Prevalence Research Group. The prevalence of diabetic retinopathy among adults in the United States. Arch Ophthalmol. 2004; 122:552-563.

6. Wong TY, Cheung N, Tay WT, et al. Prevalence and risk factors for diabetic retinopathy. The Singapore Malay Eye Study. Ophthalmology. 2008; 15:1869-1875.

7. Wang FH, Liang YB, Zhang F, et al. Prevalence of diabetic retinopathy in rural China: the Handan Eye Study. Ophthalmology. 2009;116:461-467.

8. Mitchell P, Smith W, Wang JJ, Attebo K. Prevalence of diabetic retinopathy in an older community. The Blue Mountains Eye Study. Ophthalmology. 1998;105:406-411.

9. Thapa SS, Thapa R, Paudyal I, et al. Prevalence and pattern of vitreo-retinal diseases in Nepal: the Bhaktapur Glaucoma Study. BMC Ophthalmol. 2013;13:9.

10. Paudyal G, Shrestha MK, Meyer JJ, Thapa R, Gurung R, Ruit S. Prevalence of diabetic retinopathy following a community screening for diabetes. Nepal Med Coll J. 2008;3:160-163.

11. Nirmalan PK, Robin AL, Katz J, et al. Prevalence of vitreo-retinal disorders in a rural population of southern India: the Aravind Comprehensive Eye Study. Arch Ophthalmol. 2004;122:581-586.

12. Pradeepa R, Anitha B, Mohan V, Ganesan A, Rema M. Risk factors for diabetic retinopathy in an Indian Type 2 diabetic population-the Chennai Urban Rural Epidemiology Study (CURES) Eye Study 4. Diabet Med. 2008;25(5):536-542.

13. Rema M, Premkumar S, Anitha B, Deepa R, Pradeepa R, Mohan V. Prevalence of diabetic in urban India: the Chennai Urban Rural Epidemiology Study (CURES) Eye Study, I. Invest Ophthalmol Vis Sci. 2005; 46:2328-2333.

14. Thapa R, Bajimaya S, Sharma S, Rai BB, Paudyal G. Systemic association of newly diagnosed proliferative diabetic retinopathy among type 2 diabetes patients presented at a tertiary eye hospital of Nepal. Nepal $J$ Ophthalmol. 2015;7(13):26-32.

15. Klein R, Klein BE, Moss SE, Davis MD, Demets DL. The Wisconsin epidemiologic study of diabetic retinopathy II. Prevalence and risk of diabetic retinopathy when age at diagnosis is less than 30 years. Arch Ophthalmol. 1984;102:520-526.

16. Moss SE, Klein R, Klein BE. Association of cigarette smoking with diabetic retinopathy. Diabetes Care. 1991;14(2):119-126.

17. Moss SE, Klein R, Klein BE. Cigarette smoking and ten-year progression of diabetic retinopathy. Ophthalmology. 1996;103(9):1438-1442.

18. Thapa R, Joshi DM, Rizyal A, Maharjan N, Joshi RD. Prevalence, risk factors and awareness of diabetic retinopathy among admitted diabetic patients at a tertiary level hospital in Kathmandu. Nepal J Ophthalmol. 2014;6(11):24-30.

19. Thapa R, Paudyal G, Maharjan N, Bernstein PS. Demographics and awareness of diabetic retinopathy among diabetic patients attending the vitreo-retinal service at a tertiary eye care center in Nepal. Nepal $J$ Ophthalmol. 2012;4(7):10-16.

20. Central Bureau of Statistics. Population census 2011. Kathmandu: Government of Nepal, National Planning Commission Secretariat; 2011.

21. Thapa SS, Rana PP, Twyana SN, et al. Rationale, methods and baseline demographics of the Bhaktapur Glaucoma Study. Clin Exp Ophthalmol. 2011;39(2):126-134.

22. Bennett S, Woods T, Liyanage WM, Smith DL. A simplified general method for cluster sample surveys in developing countries. World Health Stat Q. 1991;44:98-106.

23. Early photocoagulation for diabetic retinopathy: ETDRS report 9. Early Treatment Diabetic Retinopathy Study Research Group. Ophthalmology. 1981;98:766-785. 
24. Report of World Health Organization/International Diabetes Federation consultation: definition and diagnosis of diabetes mellitus and intermediate hyperglycaemia. 2006. Available from: http:/www.who.int/ diabetes/publications/diagnosis_diabetes2006/en/. Accessed 2006.

25. Sunita M, Desai S, Vinay P, et al. Aditya Jyot-Diabetic Retinopathy in Urban Mumbai Slum Study (AJ-DRUMSS): study design and methodology-report 1. Ophthalmic Epidemiol. 2014;21(1):51-60.

26. Sunita M, Singh AK, Rogye A, et al. Prevalence of diabetic retinopathy in urban slums: the Aditya Jyot Diabetic Retinopathy in Urban Mumbai Slums Study - report 2. Ophthalmic Epidemiol. 2017;24(5):303-310.

27. Ting DS, Cheung GC, Wong TY. Diabetic retinopathy: global prevalence, major risk factors, screening practices and public health challenge: a review. Clin Exp Ophthalmol. 2016;44(4):260-277.

28. Hirvela H, Laatikainen L. Diabetic retinopathy in people aged 70 years or older. The Oulu Eye Study. Br J Ophthalmol. 1997;81:214-217.

29. Lee CC, Stolk RP, Adler AI, et al. Association between alcohol consumption and diabetic retinopathy and visual acuity-the AdRem Study. Diabet Med. 2010;27(10):1130-1137.

30. Moss SE, Klein R, Klein BE. The association of alcohol consumption with the incidence and progression of diabetic retinopathy. Ophthalmology. 1994;101(12):1962-1968.

31. Young RJ, Mcculloch DK, Prescott RJ, Clarke BF. Alcohol: another risk factor for diabetic retinopathy? Br Med J (Clin Res Ed). 1984;288(6423): 1035-1037.
32. Zhu W, Meng Y, Wu Y, Xu M, Lu J. Association of Alcohol intake with risk of diabetic retinopathy: meta-analysis of observational studies. Sci Rep. 2017;7:4

33. Fenwick EK, Ryan JX, Kiddman E, et al. Moderate consumption of white and fortified wine is associated with reduced odds of diabetic retinopathy. J Diabetes Complications. 2015;29(8):1009-1014.

34. Thapa R, Bajimaya S, Paudyal G, et al. Population awareness of diabetic eye disease and age related macular degeneration in Nepal: the Bhaktapur Retina Study. BMC Ophthalmol. 2015;15:188.

35. Thapa R, Bajimaya S, Pradhan E, Paudyal G. Agreement on diabetic retinopathy grading in fundus photographs by allied ophthalmic personnel as compared to ophthalmologist at a community setting in Nepal. Nepal J Ophthalmol. 2017;9(17):43-50.

36. Thapa R, Bajimaya S, Bouman R, et al. Intra- and inter-rater agreement between an ophthalmologist and mid level ophthalmic personnel to diagnose retinal diseases based on fundus photographs at a primary eye center in Nepal: the Bhaktapur Retina Study. BMC Ophthalmol. 2016;16:112.

37. Gulshan V, Peng L, Coram M, et al. Development and validation of a deep learning algorithm for detection of diabetic retinopathy in retinal fundus photographs. JAMA. 2016;316:2402-2410.

38. Perumalsamy N, Prasad NM, Sathya S, Ramasamy K. Software for reading and grading diabetic retinopathy: Aravind Diabetic Retinopathy Screening 3.0. Diabetes Care. 2007;30:2302-2306
Clinical Ophthalmology

\section{Publish your work in this journal}

Clinical Ophthalmology is an international, peer-reviewed journal covering all subspecialties within ophthalmology. Key topics include: Optometry; Visual science; Pharmacology and drug therapy in eye diseases; Basic Sciences; Primary and Secondary eye care; Patient Safety and Quality of Care Improvements. This journal is indexed on

\section{Dovepress}

PubMed Central and CAS, and is the official journal of The Society of Clinical Ophthalmology (SCO). The manuscript management system is completely online and includes a very quick and fair peer-review system, which is all easy to use. Visit http://www.dovepress.com/ testimonials.php to read real quotes from published authors. 